\title{
A Comparative Study of Suicide Tendency among Students in Relation to gender and residential area
}

\author{
Prof. Jayesh N. Bhalala*
}

\section{ABSTRACT}

The goal of the present study was to note the effect of the gender (Male/ Female) and residential area (Rural/ Urban) on the suicide tendency of students. In view to above purpose the sample of 120 was selected by random sampling method. Suicide tendency Inventory standardized by Dr. G. R. Meghnathi (2002) Among the Students of Rajkot city and from its rural areas, was referred to have data regarding their suicide tendency and all the tow individual factors, obtained information was statistically analyzed by ' $t$ '-test effects were discovered. According to the results show that there is significant difference existed between male and female students, ' $t$ '-value 1.96 has been found significant at 0.05 level. So we concluded that female students showed higher level of suicide tendency then male students. Showed significant effect of area on suicide tendency. The' $t$ '-value 3.39 has been found significant at 0.01 level. So we concluded that urban students showed higher level of suicide tendency then rural students.

Keywords: Suicide Tendency, Gender and Residential Area

\section{INTRODUCTION}

One of the basic desires of men is know of things around him. He wants to understand fully the things of the world. He asks so many questions such as why? How? When? of a thing. He is desirous of finding answers of such questions. The aim of the present investigation is effort to understand to the Suicidal Tendency in students of gender (Male/ Female) and residential area (Rural/ Urban)

Adolescence is very important period of one's life. It is stage when rapid changes take places. The individual's physical, mental, social, moral and spiritual outlooks undergo revolutionary changes. Such changes during adolescence are more rapid than during infancy. Due to this growth human personality develops new dimensions. Many parents fail to assess these changes and generally shoe difference because they do not like to take their control over their children. This attitude creates many difficulties for the adolescents. During adolescence the individual wants to take indecency and his emotional development will suffer and he may become short=tempered and aggressive.

Lecturer in Psychology, Smt. R. R. Patel Manila College, Astron Soct., Kalawad Road, RAJKOT, Gujarat, India

(C) 2014 J Bhalala; licensee IJIP. This is an Open Access Research distributed under the terms of the Creative Commons Attribution License (http://creativecommons.org/licenses/by/2.0), which permits unrestricted use, distribution, and reproduction in any Medium, provided the original work is properly cited. 


\section{A Comparative Study of Suicide Tendency among Students in Relation to gender and residential area}

Consequently, social developments on correct lines will not be possible. Thus, the physical development of an adolescent is closely related to other developments. Here, one point is very important to discuss that physical disability is affect the behavior of $\mathrm{s}$ to adolescents.

The sources of frustration are many and diversified; the basic source which lies within many individual is mainly his/her personal disability, if any. Actually, the human organism is composed of numerous systems. Damage to any one of them may give rise to a disability. Every disability leads to problems in the entire spectrum of activities of an individual which is directly responsible for the behaviors that are called maladaptive. Evidence indicates and disorganizing (Shontz, 1970). It also plays a big role in the amount and direction of frustration. The reason behind this fact is that any defect which is derived from non-participation in activities common to those engaged in by normal individual is liable to create resentment and frustration (Wasserman and Rhiannon 1985). It is likely to influence his adjustment to people, circumstances and his self-perception which makes him more emotionally disturbed and frustrated.

Suicidal tendency has wide range of self-destructive behavior such as a personality trait; indicate some negative characteristics such as feelings of restlessness Boredom, lack of interest, vague fears and Anxieties etc. conflictive thought rebate to tension, Anxiety, and conflict, painful thought etc.

Dubey surendra N (1984) has studied on reaction to frustration among physically handicapped

young adults in K. S. Saket Post Gradate Coll, India, studied with an Indian adaptation of the Rosenstein Picture- Frustration Study was administered to 25 physically handicapped and 25 nonhandiapped males(aged 18-22 yrs) matched on age, education, caste, and socionomic status(SES). Physically handicapped Ss were more ego defensive, "extragressive" and obstacle dominate as well as less "introgrSsessive" and need permissive than were nonhandiapped.

\section{OBJECTIVES OF STUDY}

1. To find signification mean difference on scores of suicide tendency with gender and residential area.

2. To explore the mean effect difference between the gender and resident areas students.

3. To suggestion steps for minimize suicide tendency.

\section{STATEMENT OF THE RESEARCH PROBLEMS}

"A Comparative Study of Suicide Tendency among Students in Relation to gender and Residential area" 


\section{VARIABLES OF STUDY}

- Independent variables

1. Gender (Male/ Female)

2. Residential area (Rural/ Urban)

- Dependent variable

1. Suicide tendency

\section{HYPOTHESES OF THEE RESEARCH STUDY}

2.Ho.1 There is no significant mean difference between Male and Female students there suicide tendency.

3.Ho.2 There is no significant mean difference between Rural and Urban aria students there suicide tendency.

\section{METHODOLOGY}

\section{Sample}

Sample Procedure Simple Random Sampling design was selected for the present research work to fulfill this purpose. Firstly, to make a list of educational institutes, witches were located in the cities of Rajkot and other rural area of both districts. Then some colleges, schools and high schools were selected randomly.

- Research Design adopted in this study

- Major Statistical Techniques used in present research work are as follows.

- To measure, significant mean difference between two variables, the t-ratio was used.

Table -1 . Sample as per the plan

\begin{tabular}{|c|c|c|c|}
\hline $\begin{array}{c}\text { Type of Gender } \\
\begin{array}{c}\text { area } \\
\downarrow \quad / / R e s i d e n t i a l\end{array}\end{array}$ & Male & Total \\
\hline & & & \\
\hline Rural & $\mathbf{3 0}$ & $\mathbf{3 0}$ & $\mathbf{6 0}$ \\
\hline Urban & $\mathbf{3 0}$ & $\mathbf{3 0}$ & $\mathbf{6 0}$ \\
\hline Total & $\mathbf{6 0}$ & $\mathbf{6 0}$ & $\mathbf{1 2 0}$ \\
\hline
\end{tabular}




\section{TOOLS}

1. Individual Information From

2. Suicide tendency Inventory

\section{RESEARCH TOOLS}

The Suicidal tendency was measured by Suicidal Tendency Scale (S T S) constructed and standardized by Bhatt and Meghnathi. The scale consists of 40 items out of which, each of the four modes of Suicidal Tendency has 10 items. The items of the scale has been selected on this basis of literature and judgment of expert, all the items of the scale are presented in simple and brisk style. S T S has four modes viz., (a) personality characteristic (b) Emotional Disturbances (c) Conflictive Thoughts, and (d) Self-harm Tendency. The preliminary scale with 80 items of STS was administered on Total Sample $(\mathrm{N}=140)$ selected items from various types of subjects group which are students of $11^{\text {th }}$ to T.Y.B.A. $(\mathrm{N}=70)$. Lieral and illiberal person $(\mathrm{N}=40)$, physically Handicapped $(\mathrm{N}=20)$, Suicidal Attempters $(\mathrm{N}=10)$. The data were analyzed according to scoring key and prepared a merit list of scores and the Lower level Group (27\%) Upper levels Group (27\%) were indicated low scores. The Middle Group was not considered in this process. Finally 40 items were selected which was indicated $50 \%$ ( or nearly about $50 \%$ ) quotient of D.V. and D.I. For the established the reliability co-efficient, the scale was administered to 160 subjects both males and females belonging to urban and rural area (Age range 16 to $30 \mathrm{yrs}$ ) the spilt-half reliability has been calculated by odd-even method. The correlation coefficient was 0.92 which indicated the STS is highly reliable. (Index of reliability was found 0.96). The test-retest reliability of this scale has also been calculated by administration twice of this scale on sample of 80 subjects the reliability coefficient was r. 0.83 (Index of reliability was 0.91 ). The validity of the scale has been calculated for the criterion validity. The scale was administered to two groups normal $(\mathrm{N}=40)$ and Abnormal $(\mathrm{N}=40)$. The t-test was applied for calculation of differences between above both groups there is ( $\mathrm{t}$ ratio found 0.01) significant differences between normal and abnormal group was indicated high scores of suicidal tendency than normal group on the scale. The obtained scores for each of the four categories varied in between 10 to 40 high scores in each category is indicated high potentially of suicidal tendency. Norms are remained to be established. The scale is prepared in Gujarati version for Gujarati speaking population.

\section{PROCEDURE AND METHOD OF ANALYSIS}

Keeping in view the purpose the present study, the data collection was made by $2 \times 2 \times 1$ factorial designed. Its analysis of t-test was done.

\section{RESULTS AND DISCUSSION:}

Table -2 , Sowing difference between the mean score 


\begin{tabular}{|c|c|c|c|c|c|c|}
\hline $\begin{array}{r}\text { Sr. } \\
\text { No. }\end{array}$ & Students & $\mathbf{N}$ & Mean & S.D & ' $\mathbf{t}$ ' & Level of Significance \\
\cline { 1 - 4 } $\mathbf{1}$ & Male & 60 & 62.01 & 9 & & \\
\cline { 1 - 4 } $\mathbf{2}$ & Female & 60 & 65.50 & 10.5 & 1.96 & 0.05 \\
\hline
\end{tabular}

It indicates in table NO. 2 that "t" value of sex difference between the Mean Ss of boys and Female turned out to be in " $t=\mathbf{1 . 9 6}$. It is $\mathbf{0 . 0 5}$ level significance. It is greatly said that difference between the Male and Female in Suicide Tendency. Female in higher than Male of Suicide Tendency.

Table -3 , Sowing difference between the mean score

\begin{tabular}{|l|c|c|c|c|c|}
\hline Residential area & N & M & SD & t & Sin. Level \\
\hline Rural & 60 & 58.58 & 7.82 & & 0.01 \\
\cline { 1 - 3 } Urban & $\mathbf{6 0}$ & $\mathbf{5 3 . 9 3}$ & $\mathbf{7 . 1 7}$ & 3.39 & \\
\hline
\end{tabular}

Table no.3 displays the type of the Residential area has the significant effect that a t-value $=\mathbf{3 . 3 9}$ is significant $\mathbf{0 . 0 1}$ level that mines Rural areas suicide tendency is higher than urban area.

\section{CONCLUSION}

1. In comparison to the male and female of suicide tendency that female are more suicide tendency than male

2. Also comparison suicide tendency in Residential area in rural areas suicide tendency is higher than urban area

\section{REFERENCES}

1. Practical consideration, Indian Journal of Clinical Psychology-15, 6-11.

2. R.G. Meghnathi (2004), Regional officer for south East Asia. New Delhi, Varma, S.K. (1988): Measurement of the positive mental health: Some Theoretical -A comparative study of suicide tendency

3. Reddy and Nagrathan (1993):, Mental health status among rural and urban teachers'. A Comparative study; Journal of the Indian Academy of applied Psychology Vol. 19, No. 1-2, P. 25-30.

4. Sell, H., Nagpal, R. (1992), Assessment of Subjective well-being inventory. World Health Organization 